\title{
Health and safety matters! Associations between organizational practices and personal support workers' life and work stress in Ontario, Canada
}

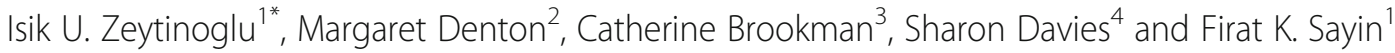

\begin{abstract}
Background: The home and community care sector is one of the fastest growing sectors globally and most prominently in mature industrialized countries. Personal support workers (PSWs) are the largest occupational group in the sector. This paper focuses on the emotional health of PSWs working in the home and community care sector in Ontario, Canada. The purpose of this paper is to present evidence on the associations between PSW' life and work stress and organizational practices of full-time and guaranteed hours, and PSWs' perceptions of support at work and preference for hours.
\end{abstract}

Methods: Data come from our 2015 survey of 1543 PSWs. Dependent variables are life and work stress. Independent variables are: objective organizational practices of full-time and guaranteed hours, and subjective organizational practices of perceived support at work, and preferred hours of work. Descriptive statistics, correlations and ordinary least square regression analyses with collinearity tests are conducted.

Results: Organizational practices of employing PSWs in full-time or guaranteed hours are not associated with their life and work stress. However, those who perceive support from their organizations are also the ones reporting lower life and work stress. In addition, those PSWs perceiving support from their supervisor report lower work stress. PSWs would like to work in their preferred hours, and those who prefer to work more hours report lower life and work stress, and conversely, those who prefer to work less hours report life and work stress.

Conclusion: For PSWs in home and community care, perceived support from their organizations and supervisors, and employment in preferred hours are important factors related to their life and work stress.

Keywords: Personal support workers, Life and work stress, Organizational practices, Support at work, Preferred hours

\section{Background}

Home and community care sector is one of the fastest growing sectors globally and most prominently in mature industrialized countries [1-3]. With the population aging, the preference to stay in one's own home, and ongoing shortages of care workers [3-7], has resulted in an increased demand for home and community care services particularly for the care services provided by personal support workers (PSWs) $[8,9]$. There is similarly a high need for elder care in nursing homes in mature industrialized

\footnotetext{
* Correspondence: zeytino@mcmaster.ca

${ }^{1}$ DeGroote School of Business, McMaster University, Hamilton, ON, Canada Full list of author information is available at the end of the article
}

countries $[10,11]$. In addition, health care sector reforms in the past few decades have resulted in reduced budgets for home and community care making it difficult for organizations to hire sufficient number of workers to provide services for increased demand $[1-6,12,13]$.

This paper focuses on home and community care services in Ontario, Canada. Home and community care services in Canada help people receive care at home or in a retirement home, and does not refer to care provided in a hospital or long-term facility such as a nursing home [14]. Home and community care services are delivered by regulated health care professionals, such as nurses and therapists, non- 
regulated workers such as personal support workers, and unpaid workers such as volunteers, and family and friends of care recipients [14]. In Canada, home and community care services are mainly delivered by provincial, territorial and some municipal governments, though individuals can purchase these services privately. The federal government also provides home and community care services to First-Nations on reserve and Inuit in designated communities, among others [14]. These services are funded through transfer payments from the federal Government to provinces, territories and some municipalities. In Ontario, where this study took place, Community Care Access Centres (CCAC) are the organizations that receive funding and distribute it to service organizations through a competitive bidding process. Personal support workers work for these service organizations or through organizations directly funded by the Local Health Integrated Networks (LHINS) The employing organizations can be private for-profit, private notfor-profit or public not-for-profit.

There is no universally accepted terminology for the PSW occupation. For example, they are called health support workers in the U.K. [15], home care workers $[16,17]$ or home health care aides in the U.S. [18, 19], home health care workers or aides in Europe [7], home care workers in Japan [3] and home care attendants in Taiwan [20]. In Canada, they used to be called home support workers [1] or visiting homemakers [21] though now they are more commonly referred to as personal support workers $[12,22,23]$. The PSW occupation is non-regulated in Canada, meaning that a licence from a regulatory body is not required to be employed in the sector [14].

Home and community care PSWs provide care to patients discharged from hospitals, the elderly including those with dementia, and persons with disabilities. The workplace of the home and community care PSWs is the home of the person receiving care. PSWs perform a variety of tasks each tailored to the needs of the person receiving care. Some of the tasks performed are: (1) activities of daily living personal care (bathing, feeding, dressing, toileting), transferring (from sit to stand, walking), light housekeeping, and child care; (2) instrumental activities of daily living - menu planning, shopping, meal preparation, providing transportation or accompanying clients, educational and recreational assistance; (3) clinical care services - measuring a client's blood pressure, taking temperature, pulse, specimens; and (4) delegated tasks - administration of suppositories, colonic irrigation, enemas (bowel disimpaction), or medication; maintaining inventories; and supervising exercise routines $[4,12,22]$.

\section{Purpose and contribution of the study}

The purpose of this paper is to present evidence on the associations between PSWs life and work stress and organizational practices, perceptions of support at work and preference for hours of work. Research shows that PSWs experience stress due to the nature of their work and work environments in Canada and elsewhere including U.S., UK, Europe, and Japan [3, 7, 11-13, 15-17, 21, 24]. Similarly, nurses, nursing aides, nursing assistants and nursing health care staff employed in elderly care in longterm care facilities/ nursing homes in Canada [25], Japan [26], Taiwan [20] Switzerland [27], Finland [28], U.S. [29] and UK [30] report stress at work. The stress in health care environments is so unique to the sector that it is sometimes referred as a 'stress of conscience' where health care staff experience a troubled conscience because they would like to provide the best quality care but are unable to do so [31] for a variety of reasons. This paper contributes to academic and practitioner knowledge by showing the relationship between life and work stress and organizational practices, worker perceptions of support at work, and preferences for hours of work of home and community care PSWs.

\section{Theoretical foundation, empirical knowledge and hypotheses}

Our research is informed by the stress coping theory of Lazarus [32] and job stress theory of Ironson [33] in developing the conceptual model and in introducing organizational practices, perceptions and preferences to be tested in the model. The experience of life and work stress is an individual experience that can vary from one person to another. According to Lazarus's transactional theory [32], when an individual is faced with a potentially stressful situation, s/he evaluates it as a threat or challenge, and depending on their coping abilities and resources, some are able to cope with stress, and others show strain. Focusing on work stress, the demand-control model of Karasek [34] states that when workers have high demands and low control at work they present symptoms of stress. PSW work is a high demand-low control work, where workers are expected to provide care in the allocated time period. The care, i.e. tasks, are usually assessed and decided upon jointly with the client and case managers for each client, while PSW supervisors oversee the scheduled work for each PSW and inform them of the clients to visit for care giving, tasks to be performed for each client, and time allocated for each task.

Empirical research has shown a number of demographic characteristics and work factors that can be associated with stress. As we present in Fig. 1, we control for the possible associations of some of those factors with stress. For demographic characteristics of gender and marital status, particularly for women, some studies find association with stress $[35,36]$ and others do not. 


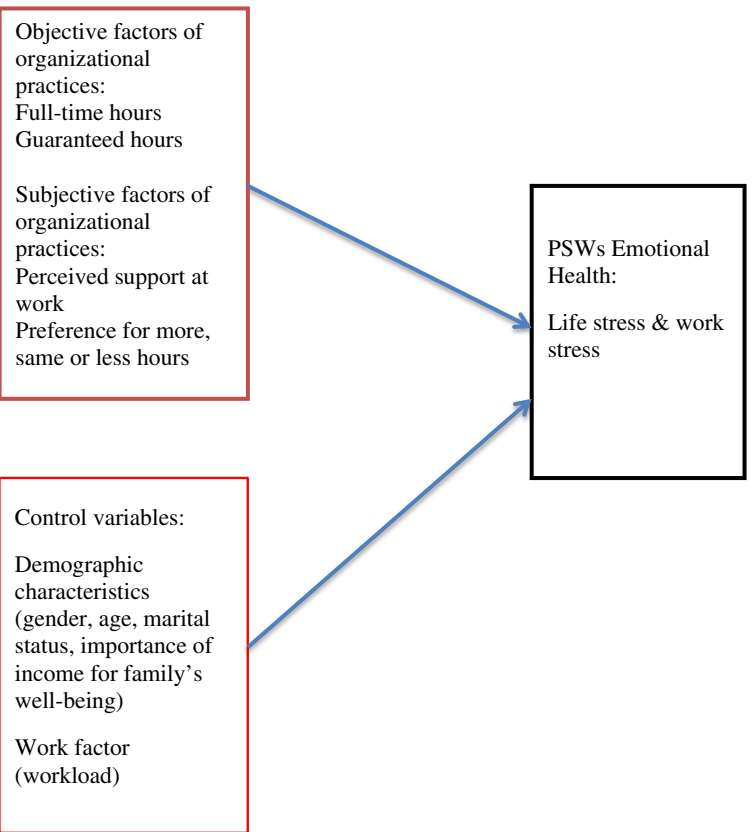

Fig. 1 The conceptual model of organizational practices associated with PSWs life and work stress

For example, our studies with PSWs show no association with gender and marital status and various health outcomes arguing that it is the work environment factors, not individual characteristics that are related to stress $[21,24]$. Age does not seem to have a clear association with stress in some studies [36] though in our studies with PSWs those who are older report lower stress [21, 24]. We also include the importance of income for the family's economic well-being as a factor to be controlled in this study. PSWs are the lowest paid workers in the health care labour force in US, and financial worries can be a source of stress [37]. In our studies of home care workers and nurses, the importance of income from the PSW work for their family's well being showed to be associated with work attitudes and behaviours and/or health [24, 38, 39]. For nurses in Ontario, Canada research showed that as the importance of income for their family's well-being increased so did their stress level [39]. The work characteristic of workload is shown to be associated with the work stress of health care workers [10, 20, 27-29, 31, 36, 38, 40, 41] and this factor is included as a control variable in our study.

As presented in Fig. 1, organizational practices can be observed as objective factors of hours of work (full-time hours or not), and whether hours are guaranteed or not. Organizational practices as seen through the lens of workers are subjective factors that can affect workers perceptions and can match or mismatch with their preferences. Subjective factors in our study are perceived support at work and preferences for hours We test the relationships of these objective and subjective factors to life and work stress .

An empirical study on the hours of work with geriatric care workers in Germany shows that as the amount of working hours per week increased there was an increase in stress and strain among workers [11]. However, for those working part-time hours, there was low stress [11]. Similarly in US, a study of female nursing home assistants showed that the odds of adverse mental health increased with increased hours of work [42]. Thus, we hypothesize that:

Hypothesis 1. Working full-time hours will be positively associated with PSWs life and work stress.

Many organizations in home and community care in Ontario, Canada hire PSWs as needed and their work hours are not guaranteed [4, 12, 13]. The organizational practice of guaranteed hours of work is security for worker, because guaranteed hours provide continuity in pay, benefits and financial security [24]. Research from other countries in similar occupations or in the health care sector show the importance of guaranteed hours for the emotional health of workers. A study from Finland with registered nurses has found insecure work contracts to be associated with reduced well-being indicators such as psychological distress [43]. In another study, nurses' perception of good work in Sweden included work security and a steady income [44]. A study in Germany also showed that predictability in hours and decreased job insecurity were important in lowering geriatric care workers stress [11]. Guaranteed hours of work can provide security to PSWs; and those who work in guaranteed hours might also be the ones reporting lower life and work stress.

Hypothesis 2. Guaranteed hours will be negatively associated with PSWs life and work stress.

A systematic review of working in nursing homes found low social support at work in smaller-scale nursing homes to affect the quality of working life [10]. Studies found support at work to be associated with lower levels of stress among nursing home workers, home care workers and nurses in Australia, Canada, Sweden and Germany [8, 10-12, 21, 24, 31, 40] though a study from US on nursing aide workers found effects of managerial and co-worker support on stress to be minor [29]. Another study from Sweden on nurses' perceptions of good work showed having pleasant and appreciative fellow workers, i.e. co-worker support, and having a fair and understanding manager, i.e. supervisor support, as important factors at work [44]. Based on these studies we hypothesize that:

Hypothesis 3. Support at work (organizational, supervisor, and/or peer support) will be negatively associated with PSWs life and work stress. 
Working in preferred employment conditions can be associated with workers' reporting low levels of stress. Our study of nurses employed in hospitals in Ontario, Canada found that it is important for these workers to be employed in their preferred hours, whether it is more, the same or less hours to retain them in the workplace [39]. Another study showed that elderly care nursing staff preferred to control their work schedules and this was related to lower strain [41]. Though our study is not on the control over work hours, we can infer from this [41] and the preferred hours study [39] that PSWs in our study would also like to work in their preferred hours. We would also argue that those who prefer to work more hours would also be the ones reporting lower life and work stress, and those preferring to work less hours would be the ones reporting higher life and work stress.

Hypothesis 4. Preference to work more hours will be negatively associated with PSWs life and work stress.

\section{Methods}

\section{Research design}

This paper is based on our Ontario-wide 2015 survey data collected under the 'The PSW Health and Safety Matters! title [hereafter the survey] (http://www.pswshaveasay.ca). The project is guided by a Research Advisory Committee (RAC) which includes the representatives from two home care organizations' associations (employer associations), two of the largest unions in the sector, a PSW employee association, a health and safety association with expertise on the occupational health of the home and community based PSWs, and the principal investigator, co-lead, and three co-investigators of the project (see acknowledgment section).

\section{Population, sample and data collection process}

The study population is composed of all PSWs employed in the home and community care sector in Ontario, Canada (estimated 26,000 ${ }^{1}[45,46]$ ). A total of 2341 PSWs responded to the vey. This study uses data from respondents who completed the entire survey (i.e., came to the last page of the online survey) and selected 'submit the survey' option, and for the print-mail survey, mailed it back to us $(n=1746)$. In the analyses, observations with missing values are excluded and, thus, the sample size used in this paper is 1543 . Using the sample size formula [47] for a population of 26,000, with $95 \%$ confidence interval and $3 \%$ margin of error we needed 1026 respondents. Our sample size for this paper well exceeds the sample size needed to accurately reflect the population (with 95\% confidence interval) and the true value the population would give to our questions (with $3 \%$ margin of error). In addition, for conducting multiple regression analyses with small effect size, our data is more than sufficient [48].

After receiving ethics approval from McMaster University Research Ethics Board (MREB-2014-132) the survey process started. The pilot testing of the understanding and completion of the survey in both an on-line format and print-mail format was conducted with 10 PSWs from St. Clair West Services for Seniors, a community services home care organization. The pilot testing did not show any issues with the survey in either format.

In collecting data, the research team used three approaches. First, we attempted to reach as many PSWs as possible by sending out email blasts by partner organizations that are members of the Research Advisory Committee; Ottawa West Community Support; and the PSW Registry. These email blasts encouraged PSWs to participate in our survey by going to the study website (http://www.pswshaveasay.ca). The project website displayed a video which explained the survey. Reminder email blasts were also sent to encourage participation. A second approach for recruitment was through the placement of advertisements on several organizations' websites and a project article distributed in many organizational newsletters to promote our survey. Some organizations also promoted our survey through Twitter. A third strategy to recruit survey participants was to incorporate strategies at the organization level. We developed several tools for organizations to use to encourage their employees to complete our survey: a flyer was provided promoting our survey which could be sent out to employees; a "newsletter article" that organizations could include in their monthly newsletters was provided; and a mini Health and Safety In-service PowerPoint presentation which incorporated our survey was developed. Organizations were invited to use these strategies to promote participation in our survey.

PSWs were asked to respond to the survey only if they were a community-based PSW. The on-line survey was collected using LimeSurvey, an on-line web application. Most responses were to the on-line survey, although some preferred print-mail surveys. Both on-line and print-mail surveys started with confirmation of consenting to participate in the survey. Although respondents were encouraged to complete the entire survey, they were not required to do so and respondents were not required to answer every question in the survey. Survey respondents were given minor incentives to complete the survey. On-line survey respondents were given an option to enter a draw to win one of several gift cards upon completion of the survey and print-mail survey participants were given a very small (amount) gift card that was mailed along with the survey. 


\section{Instrument and measures}

The instrument of the study was the self-completion of The PSW Health and Safety Matters Survey put together by the research team using their own questions, and theirs and others' published scales [49]. Unless specifically explained below, all variables were measured on a five-point Likert scale anchored with ' 1 = strongly disagree' to ' 5 = strongly agree'. The equal interval assumption is used for the Likert scale measurement of dependent, independent and control variables. To create scores for each scale, responses to each item were summed together, with some items reverse coded as suggested by the scale developer. In constructing the scales, in order to reduce missing data, if missing values for each item in a scale were less than $5 \%$, we replaced the missing values in the item with the mean of the item. As referenced below, all scales used in this paper have been previously developed and validated in earlier studies.

Dependent variables are life and work stress. Life stress is worded as 'thinking about the amount of stress in your life, would you say that most days are...?' and work stress is worded as 'working as a PSW in the community, in the past twelve months, would you say most days at work were...?' Responses are coded on a fivepoint Likert scale with ' $1=$ not at all stressful' to ' $5=$ extremely stressful'. These questions are from the Canadian Community Health Survey (CCHS) [50].

Organizational practices are independent variables. Objective measures of organizational practices are providing full-time hours and guaranteed hours. The full-time hours variable is from the question 'approximately how many hours do you work per week as a PSW in the community?' with those answering $30 \mathrm{~h}$ or more coded as full-time hours, using an approach similar to Statistics Canada's calculation of full-time versus part-time hours. The guaranteed hours variable is from the question 'are your hours guaranteed?' with response as a dummy variable, coded 1 = yes, $0=$ no. Subjective measures of organizational practice are support at work and preference for hours. Support at work is examined as perceived organizational, supervisor and peer support. Organizational support and supervisor support are, six-item and sevenitem scales, based on Denton et al. [21] and Zeytinoglu et al. [38] with two questions included from our survey [49]. Peer support is from Denton et al. [21] with four items. A sample item for each scale is 'your organization supports you in times of personal crisis, illness or needing time off to help care for other family members', 'you have the opportunity to talk openly with your supervisor about workrelated problems' and 'your co-workers are helpful in getting the job done.' Measurements of scales are as explained above. The Cronbach's $\alpha$ s for scales indicate high internal reliability (See Table 1 along the diagonal). Preference for more, same or less hours is based on the question 'would you prefer to work more or less hours per week as a PSW in the community?' with response items of more, same or less hours per week (each as a dummy variable, coded 1 = yes, 0 = else).

\section{Control variables}

Demographic characteristics are gender, age, marital status, and importance of income for family's economic wellbeing. Gender is a binary variable (female $=1$, male $=0$ ), with females as the majority of workers in the sample (93\%). Age is coded as number of years with respondents' average age being 49. Marital status is measured as $1=$ married $/$ common law relationship, $0=$ other, with $66 \%$ married/common law. Importance of income for family's economic wellbeing is measured on a fivepoint Likert scale as explained above; with this issue being very important for respondents $(M=4.56, S D=0.75)$. The percentage distribution of gender, age and marital status are similar to those reported in earlier studies [1, $12,21]$. For the work factor, workload is a scale including both physical and psychosocial work environment items [21, 24]; a sample item is "you have too much to do on the job." The scale has high internal reliability $(\alpha=.89)$ and results show the workload is heavy for PSWs $(M=22.08, S D=5.76$, scale range: 7 to 35$)$.

\section{Analysis}

Descriptive statistics, correlations and Ordinary Least Squares (OLS) regressions are conducted. Descriptive statistics and correlations are presented in Table 1, and OLS regression results are presented in Table 2 . The subjectively assessed variables may not be completely independent from each other, and thus collinearity diagnostics (tolerance and variance inflation factor analyses) were also conducted. Collinearity with dependent variables was not found. STATA 14 is used in the analysis.

\section{Results \\ Descriptive statistics}

As presented in Table 1, PSWs report that most days in their lives and at work were a bit stressful in the past 12 months. Working full-time hours is more prominent among the PSWs, however, 41\% work part-time hours. A large percentage of PSWs work with no guaranteed hours and only $41 \%$ report having guaranteed hours. PSWs strongly agree that their organization, their supervisors, and co-workers support them at work. Half prefer to work more hours, close to the other half prefer the same hours of work, and only $7 \%$ prefer to work less hours.

\section{Correlations}

Table 1 shows correlations between dependent and independent variables. Life stress is significantly and positively 
Table 1 Descriptive statistics and correlations between life stress and work stress (dependent variables) and organizational practices, perceptions and preferences (independent variables)

\begin{tabular}{|c|c|c|c|c|c|c|c|c|c|c|}
\hline Variables & M (SD) & 1 & 2 & 3 & 4 & 5 & 6 & 7 & 8 & 9 \\
\hline 1. Life stress & $2.908(.860)$ & - & & & & & & & & \\
\hline 2. Work stress & $2.954(.912)$ & 0.507 & - & & & & & & & \\
\hline 3. Full-time hours & $.593(.491)$ & -0.001 & 0.058 & - & & & & & & \\
\hline 4. Guaranteed hours & $.406(.491)$ & -0.018 & -0.021 & 0.190 & - & & & & & \\
\hline 5. Organizational support & $20.823(4.570)$ & -0.242 & -0.306 & 0.025 & 0.070 & 0.81 & & & & \\
\hline 6. Supervisor support & $24.859(6.700)$ & -0.174 & -0.263 & 0.024 & 0.065 & 0.710 & 0.94 & & & \\
\hline 7. Peer Support & $13.645(3.434)$ & -0.113 & -0.100 & 0.089 & 0.146 & 0.428 & 0.457 & 0.85 & & \\
\hline 8. Prefer more hours & $.509(.500)$ & -0.046 & -0.055 & -0.269 & -0.245 & -0.008 & -0.026 & -0.073 & & \\
\hline 9. Prefer same hours & $.415(.493)$ & -0.036 & -0.035 & 0.199 & 0.226 & 0.084 & 0.077 & 0.108 & -0.858 & \\
\hline 10. Prefer less hours & $.0758(.265)$ & 0.153 & 0.170 & 0.138 & 0.043 & -0.142 & -0.094 & -0.063 & -0.292 & -0.241 \\
\hline
\end{tabular}

Note: Cronbach's a values are presented in italics along the diagonal. Correlation coefficients at the .05 or lower level of significance are in bold. $n=1543$

correlated with work stress, and we note that the correlation is particularly high. Correlations between life stress and independent variables show that organizational, supervisor and peer support are significantly and negatively, and preference for less hours is significantly and positively correlated with life stress. Work stress shows the same pattern with the additional factors of working full-time hours showing significant and positive correlation and preference for more hours showing significant and negative correlation. Correlations between dependent, independent and control variables are also conducted (results are available from the first author).

\section{Regressions}

As presented in Table 2, we test Hypotheses 1-4 for each dependent variable, controlling for possible associations of demographic and work factors. Starting with the second column titled life stress, as hypothesized, organizational

Table 2 Organizational practices, perceived support at work, and preference for work hours associated with personal support workers' life stress and work stress (OLS regressions)

\begin{tabular}{|c|c|c|c|c|}
\hline \multirow[t]{2}{*}{ Variables } & Life stress & Life stress & Work stress & Work stress \\
\hline & $B(S E)$ & $\beta$ & $B(S E)$ & $\beta$ \\
\hline Constant & $3.017(.207)^{c}$ & N/A & $2.134(.197)^{c}$ & N/A \\
\hline \multicolumn{5}{|l|}{ Objective organizational practices: } \\
\hline Full-time hours & $-.077(.045)$ & -.044 & $-.005(.043)$ & -.003 \\
\hline Guaranteed hours & $.022(.044)$ & -.012 & $-.037(.042)$ & -.020 \\
\hline \multicolumn{5}{|l|}{ Subjective organizational practices: } \\
\hline Organizational support & $-.028(.007)^{c}$ & -.147 & $-.021(.006)^{c}$ & -.103 \\
\hline Supervisor support & $.001(.005)$ & -.009 & $-.011(.004)^{\mathrm{b}}$ & -.082 \\
\hline Peer support & $-.008(.007)$ & -.033 & $.005(.007)$ & .020 \\
\hline Preference for more hours & $-.105(.046)^{\mathrm{a}}$ & -.061 & $-.108(.044)^{\mathrm{a}}$ & -.059 \\
\hline Preference for same hours & Reference & Reference & Reference & Reference \\
\hline Preference for less hours & $.295(.082)^{c}$ & .091 & $.242(.079)^{b}$ & .070 \\
\hline \multicolumn{5}{|l|}{ Control variables: } \\
\hline Gender & $.059(.083)$ & .017 & $.019(.079)$ & .005 \\
\hline Age & $-.006(.002)^{c}$ & -.078 & $-.003(.002)$ & -.042 \\
\hline Marital status & $.077(.044)$ & .042 & $.031(.042)$ & .016 \\
\hline Importance of income for family's economic wellbeing & $.180(.046)^{c}$ & .097 & $.172(.044)^{c}$ & .087 \\
\hline Workload & $.032(.004)^{c}$ & .212 & $.069(.004)^{c}$ & .434 \\
\hline Adj. $R^{2}$ & .13 & & .30 & \\
\hline$n$ & 1543 & & 1543 & \\
\hline
\end{tabular}

${ }^{a}$ Statistically significant at the .05 level; $^{\mathrm{b}}$ at the .01 level; ${ }^{\mathrm{c}}$ at the .001 level 
support (Hypothesis 3) and preference for more hours (Hypothesis 4) are negatively and significantly, and preference for less hours is positively and significantly associated with life stress. Other hypothesized associations are not significant. The magnitude of standardized coefficients $(\beta \mathrm{s})$, presented in third column titled life stress, show that after workload, organizational support is important for PSWs, and importance of earnings for family's economic well-being, and preference for more hours are important factors associated with life stress. The variables in the model explain $13 \%$ of variance (Adj. $R^{2}=0.13$ ).

In column 4 titled work stress, the regression analysis shows that, as hypothesized, organizational and supervisor support (Hypothesis 3) and preference for more hours (Hypothesis 4) are negatively and significantly, and preference for less hours is positively and significantly associated with work stress. Other hypothesized associations are not significant. The magnitude of standardized coefficients $(\beta s)$, in column 5 , show that after workload, organizational support is important for PSWs, and after importance of earnings for family's economic well-being, supervisor support, preference for less hours, and preference for more hours are important factors associated with work stress. The variables in the model explain $30 \%$ of work stress for PSWs (Adj. $R^{2}=0.30$ ).

\section{Discussion}

\section{Main findings}

With respect to life stress, as hypothesized, PSWs perceiving organizational support and preferring to work more hours are also the ones reporting less stress in their lives, and those preferring to work less hours are also the ones reporting life stress. Focusing on work stress, we find that, as hypothesized, PSWs perceiving support from their organization and supervisor are also the ones reporting less work stress. This finding supports earlier studies in nursing [10] focusing on nursing home workers, home care workers and nurses in Australia, Canada, Sweden and Germany [8, 10-12, 21, 24, 31, 40, 44]. In addition, as hypothesized, PSWs preferring more hours report low levels of work stress, and conversely, those who prefer less hours report higher levels of work stress. This finding is in line with earlier studies on nurses preferences in hours and retention [39]. The results of this study also supports an earlier study that showed control over work schedules to be related to lower strain [41]. However, contrary to our hypotheses, neither the full-time hours nor the guaranteed hours are related to life and work stress reported by the PSWs in our study. These findings do not support earlier studies on related occupations of nurses, nursing home aides and home care workers in other countries [11, 24, 42-44].

\section{Implications}

Whether working full-time or part-time, or having guaranteed hours or not, are not related to PSWs life and work stress. It is their perceptions of support at work and preference for working more or less hours that is related to their life and work stress, similar to findings in related health care occupations in other countries $[8,10-12,21,22,24,40,41]$. We know that community based organizations typically have a high PSW to supervisor ratio which is both a result of funding and organizational structures [12]. With the ongoing challenge of limited funding for other than direct client service (e.g. very little administrative/ planning funding), decision-makers have the opportunity to create and test out different models of PSW worker support [51]. In some home and community care organizations PSW Team Leads are being used to support other PSWs for particular tasks and training [52]. With more clients needing medication management, decision-makers need to find models of support in order to grow PSW expertise and assist in their experience of working in healthier work environments, particularly in a less stressful work environment, which can, in turn, have a spillover effect on life stress. Recognizing that not all PSWs will receive the training necessary to deliver this more complex type of care nor feel comfortable with this type of care, there exists an opportunity for decision-makers to work with PSWs to develop new structures for peer and supervisory support beyond the existing status quo of PSW to supervisor ratio. Perceptions of such support at work, whether it comes from the organization or the supervisor, could be related to PSWs reporting lower life and work stress. In addition, Ontario government's recent budget commitment to partnering with labour unions and employers to support PSW training can address the workers concerns of the delivery of complex care and can be associated with lower stress levels among PSWs [53].

The study showed that PSWs preference for hours of work, whether more or less, is related to their emotional health. This would denote an opportunity for decisionmakers to consider co-ordinating the PSW workforce based on desired number of work hours. The association of the hours with life and work stress lends itself to a healthier workforce by catering to the preferences of each worker. This can take more administrative time but the end result of a healthier workforce is, in our view, worth the managerial time.

Strengths, limitations, and suggestions for future research This study has a number of strengths and limitations and future research directions derived from the results. Our study is the first province-wide data collection of occupational health and safety of PSWs in 
Ontario. The PSWs are a large occupational group not only in Ontario but also in Canada, and there is no data that is available to analyze the relationship between their working conditions and health [54]. The strength of our data is the number of respondents. The sample size is statistically representative of Ontario's home and community care PSWs, and the sample size is sufficiently large to allow us to do the analyses with many dependent and independent variables and controlling for many other factors [47, 48]. There is, however, a limitation, and that is, there is no PSW-specific data collected by the government's health and safety agency, Workplace Safety and Insurance Board (WSIB) of Ontario to compare the work and life stress reported by our respondents. We recommend WSIB to be more specific in its data collection on this significant and increasing number of workers in Ontario and collect data on emotional and physical health of PSWs. Perhaps a national level-data collection, through Statistics Canada, on PSWs' work, health and safety can be considered as well. Another limitation of our study is that we were not able to collect organization-specific data and match individual respondents with data from their employers. We recommend future studies to build on our study and extend it by collecting a matched employer-employee data.

\section{Conclusion}

This study provides a comprehensive analysis of many factors that are related with PSWs emotional health of life and work stress. The study shows that organizational practices and how they are perceived and preferred by the PSWs are related to reporting good or poor emotional health. Particularly, our study indicates the importance of perceived support at work and working in preferred hours to be related to reporting positive health. It appears that it is not hours of work or having guaranteed hours, but PSWs perception of support at work and preferences for work hours that are related to their life and work stress. Based on findings we recommend that decision-makers pay particular attention to each individual PSWs perceptions and preferences in order to provide healthy and safe work environments for these workers. Perhaps decision-makers could use these findings as an opportunity to work together with PSWs to develop new models for client care delivery and scheduling of hours as well as developing new infrastructure models for improved supervisory and/or peer support. Our findings make important contributions to both academic and practitioner knowledge, highlighting the importance of support at work and employment in preferred hours associated with workers reporting of positive emotional health outcomes.

\section{Endnotes}

${ }^{1}$ This number is a composite derived from information collected from a variety of sources, including reports on long-term care facilities, employer and association websites and relevant studies. Three factors may affect its accuracy. 1) The number of PSWs hired privately, making total employment potentially higher. 2) Some individuals who perform the same core tasks as many PSWs may work under other job titles and, therefore, not identify with the occupational group. This would reduce the reported size of the workforce. 3) Some employers record full-time equivalent (FTE) positions rather than full-time staff. This potentially inflates their 'head-count' where, for example, a single PSW could pick up double shifts for one or more employers.

\section{Abbreviations \\ CCHS: Canadian Community Health Survey; CUPE: Canadian Union of Public Employees; OCSA: Ontario Community Support Association; OHCA: Ontario Home Care Association (Home Care Ontario); OPSWA: Ontario Personal Support Worker Association; PSHSA: Public Services Health \& Safety Association; PSNO: Personal Support Network of Ontario; PSWs: Personal Support Workers; SEIU: Service Employees International Union; the survey: The PSW Health and Safety Matters Survey; WSIB: Workplace Safety and Insurance Board}

\section{Acknowledgements}

This study is funded by Ontario Ministry of Labour Research Opportunities Program (Proposal \#13-R-030). The funder had no role in the design, execution and writing of this study. The authors would like to thank the PSWs who shared their experience with us by responding to our survey, co-investigators of the grant Susan VanderBent and Patricia Boucher, the Research Advisory Committee members (Patricia Boucher, Advanced Gerontological Education, St. Peter's Hospital; Brigid Buckingham, SEIU Healthcare; Henrietta Van hulle, PSHSA; Janitha Joseph, CUPE, Local Union 3358-01; Margaret McAlister, OHCA; Wendy Robertson, St. Clair West Services for Seniors; Deborah Simon, OCSA; Susan VanderBent, OHCA; Ronda Dickie, PSW Representative, PSNO; and Stefanie Nucci, PSW Representative, OPSWA) for their advisory role in the design and execution of the project. The Research Advisory Committee assisted in the survey distribution through e-mail blasts, newsletter inserts and a customized health and safety training presentation. Special thanks to Steve De Lisser for graphic design, communications assistance, and suggesting the survey title that is also part of the title of this paper as well as the project logo. Special thanks to Bruno Marsala for the design, development and maintenance of the study micro website and contents including the production of the project website promotional video.

\section{Availability of data and materials}

The dataset this paper is based on is the original data collected and owned by Drs. Zeytinoglu, Denton and Brookman. This data can be available only after the owners have completed using the data for their submissions (journal articles and other media outputs).

\section{Authors' contributions}

IUZ, MD and CB were responsible for study conception and design, obtaining funding from Ontario Ministry of Labour and responsible of overall leadership of the study. IUZ, MD, CB, SD designed the survey. CB, SD, IUZ, and MD managed data collection. SD prepared data for analysis. FS, SD, and IUZ were responsible of data analysis and interpretation of results for this paper. MD and CB contributed to the discussion. IUZ drafted the manuscript, all authors contributed to revisions of various sections of earlier drafts. All authors read and approved the final manuscript.

Competing interests

The authors declare that they have no competing interests. 


\section{Consent for publication}

No individual person's data is shown in this paper. Only aggregate information is provided. For online survey, survey participants agreed to participate by consenting at the beginning of the survey and 'clicking' submit button at the end of the survey. For print mail-out survey, sending it to researchers was considered as consent and clearly indicated to the participants in the 'study information and consent page'. For more see www.pswshaveasay.ca.

\section{Ethics approval and consent to participate}

This research is reviewed and approved by McMaster Research Ethics Board protocol \#MREB-2014-132.

\section{Publisher's Note}

Springer Nature remains neutral with regard to jurisdictional claims in published maps and institutional affiliations.

\section{Author details}

'DeGroote School of Business, McMaster University, Hamilton, ON, Canada. ${ }^{2}$ Department of Health, Aging \& Society and Gilbrea Centre, McMaster University, Hamilton, ON, Canada. ${ }^{3}$ Catherine Brookman Consulting \& Associates, Hamilton, ON, Canada. ${ }^{4}$ McMaster University, Hamilton, ON, Canada.

Received: 20 October 2016 Accepted: 5 June 2017 Published online: 21 June 2017

\section{References}

1. Keefe JM, Knight L, Martin-Mathews A, Le'gare' J. Key issues in human resource planning for home support workers in Canada. Work. 2011:40:21-8.

2. Genet N, Kroneman M, Boerma WGW. Explaining governmental involvement in home care across Europe: an international comparative study. Health Policy. 2013:110:84-113.

3. Broadbent K. 'I'd rather work in a supermarket': privatization of home care work in Japan. Work Employ Soc. 2014:28:702-17.

4. Denton M, Zeytinoglu IU, Davies S, Hunter D. Where have all the home care workers gone? In: Beach C, editor. Health services restructuring: new evidence and new directions. Kingston: John Deutch Institute for the Study of Economic Policy/McGill-Queen's Press; 2007. p. 245-68.

5. Arai H, Ouchi $Y$, Toba K, Endo T, Shimokado K, Tsubota K, et al. Japan as the front-runner of super-aged societies: perspectives from medicine and medical care in Japan. Geriatr Gerontol Int. 2015;15:673-87.

6. Wetzel K, Bach S, Bray M, White N. Labour relations and health reform. Hampshire: Palgrave Macmillan; 2005

7. Van de Weerdt C, Baratta R. New working conditions and consequences on activity of home health care workers. Work. 2012;41:1-4.

8. Lee CY, Beanland C, Goeman D, Johnson A, Thorn J, Koch S, et al. Evaluation of a support worker role, within a nurse delegation and supervision model, for provision of medicines support for older people living at home: the workforce innovation for safe and effective (WISE) medicines care study. BMC Health Serv Res. 2015;15:460.

9. Genet N, Boerma WGW, Kringos DS, Bouman A, Francke AL, Fagerström C, et al. Home care in Europe: a systematic literature review. BMC Health Serv Res. 2011;11:207.

10. Vermeerbergen L, Van Hootegem G, Benders J. A comparison of working in small-scale and large-scale nursing homes: a systematic review of quantitative and qualitative evidence. Int J Nurs Stud. 2017;67:59-70.

11. Nübling M, Vomstein M, Schmidt SG, Gregersen S, Dulon M, Nienhaus A. Psychosocial workload and stress in the geriatric care. BMC Public Health. 2010;10:428

12. Brookman CA. The personal support worker improving work experience - a comparison across two health care sectors. Unpublished doctoral dissertation. Ontario: University of Toronto; 2007.

13. Denton M, Zeytinoglu IU, Kusch K, Davies S. Market-modelled home care: impact of job satisfaction and propensity to leave. Canadian Public PolicyAnalyse De Politiques XXXIII Supplement. 2007:S81-99.

14. Home and Community Health Care. Government of Canada. https://www. canada.ca/en/health-canada/services/home-continuing-care/homecommunity-care.html (Accessed on 30 Apr 2017).

15. Saks M. Personal Support Workers in the UK. Paper presented at Public Services Health and Safety Association, PSW Research Symposium. Toronto; 2016.
16. Bartoldus E, Gillery B, Sturges PJ. Job-related stress and coping among home care workers with elderly people. Health Soc Work. 1989:14:204-10.

17. Sarnia LW, Ellenbecker CH, Friedman DH, Dick K. Home care nurses' experiences of job stress \& considerations for the work environment. Home Health Care Serv Quart. 2012;31:243-65.

18. Boris E, Klein J. Caring for America: home health Workers in the Shadow of the welfare state. Oxford: Oxford University Press; 2015.

19. Gleason HP, Boerner K, Barooah A. Supportinghome health aides through a client death: the role of supervisors and coworkers. Geriatr Nurs. 2016:34:278-83.

20. Hsu H-C, Kung Y-W, Huang H-C, Ho P-Y, Lin Y-Y, Chen W-S.Work stress among nursing home health care attendants in Taiwan: a questionnaire survey. Int J Nurs Stud. 2007; 44:736-746.

21. Denton M, Zeytinoglu IU, Webb S, Lian J. Job stress and job dissatisfaction of home care workers in the context of health care restructuring. Int J Health Serv. 2002;32:327-57.

22. Zeytinoglu IU, Denton M, Brookman C, Plenderleith J. Task shifting policy in Ontario, Canada: does it help personal support workers' intention to stay? Health Policy. 2014:117:179-86.

23. Personal Support Worker Program Standard. Ontario Ministry of Advanced Education and Skills Development. http://www.tcu.gov.on.ca/pepg/ audiences/colleges/progstan/health/supwork.html. Accessed 30 Apr 2017.

24. Zeytinoglu IU, Denton M, Plenderleith J, Chowhan J. Associations between workers' health, non-standard employment and insecurity: the case of home care workers in Ontario, Canada. Int J Hum Resour Manag. 2015;26: 2503-22. http://dx.doi.org/10.1080/09585192.2014.1003082

25. Syed I, Daly T, Armstrong P. How do work hierarchies and strict divisions of labour impact care workers' experiences of health and safety? Case studies of long term care in Toronto. J Nurs Home Res Sci. 2016;2:41-9.

26. Hirata $\mathrm{H}$, Harvath TA. The relationship between exposure to dementia-related aggressive behavior and occupational stress among Japanese care workers. Gerontol Nurs. 2015:41:38-46.

27. Dhaini SR, Zuniga F, Ausserhofer D, Simon M, Kunz R, De Geest S, et al. Care workers health in Swiss nursing homes and its association with psychosocial work environment: a cross-sectional study. Int J Nurs Stud. 2016:53:105-15.

28. Elovainio M, Heponiemi T, Kuusio H, Jokela M, Aalto A-M, Pekkarinen L, et al. Job demand and job strain as risk factors for employee wellbeing in elderly care: an instrumental variables analysis. Eur J Pub Health. 2015;25:103-8.

29. Jetha A, Kernan L, Kurowski A. Conceptualizing the dynamics of workplace stress: a systems-based study of nursing aides. BMC Health Serv Res. 2017;17:12

30. Turner N, Hershcovis MS, Reich TC, Totterdell P. Work-family interference, psychological distress, and workplace injuries. J Occup Organ Psychol. 2014:87:715-32

31. Glasberg AL, Eriksson S, Norberg A. Burnout and 'stress of conscience' among health care personnel. J Adv Nurs. 2007:57:392-403.

32. Lazarus RS. Theory-based stress measurement. Psychol Inq. 1990;1:3-13.

33. Ironson G. Work, job stress, and health. In: Zedeck S, editor. Work, families and organizations. San Francisco: Jossey-Bass, Inc.; 1992. p. 35.

34. Karasek RA, Theorell T. Healthy work: stress, productivity, and the construction of working life. New York: Basic Books; 1990

35. European Agency for Safety and Health at Work. Gender issues in safety and health at work: a review. Luxembourg: Office for Official Publications of the European Communities: 2003

36. European Foundation. Work-related stress. European Foundation for the Improvement of Living and Working Conditions: Dublin; 2010.

37. Stone R, Weiner J. Who will care for us? Addressing the long-term care workforce crisis. Washington, DC: Urban Institute and the American Association of Homes \& Services for the Aging; 2001

38. Zeytinoglu IU, Denton M, Davies S, Baumann A, Blythe J, Boos L. Associations between work intensification, stress and job satisfaction: the case of nurses in Ontario. Relat Indust/ Indust Relat. 2007:62:201-25.

39. Zeytinoglu IU, Denton M, Davies S, Baumann A, Blythe J, Boos L. Retaining nurses in their employing hospitals and in the profession: effects of job preference, unpaid overtime, importance of earning and stress. Health Policy. 2006;79:57-72.

40. Gao F, Newcombe P, Tilse C, Wilson J, Tuckett A. Models for predicting turnover of residential aged care nurses: a structural equation modelling of secondary data. Int J Nurs Stud. 2014;51:1258-70. 
41. Schmidt K-H, Diestel S. Differential effects of decision latitude and control on the job demands - strain relationship: a cross-sectional survey study among elderly care nursing staff. Int J Nurs Stud. 2011;48:307-17.

42. Geiger-brown J, Muntaner C, Lipscomb J, Trinkoff A. Demanding work schedules and mental health in nursing assistants working in nursing homes. Work Stress. 2004;18:292-304.

43. Elovainio M, Kuusio H, Aalto A, Sinervo T, Heponiemi T. Insecurity and shiftwork as characteristics of negative work environment: psychosocial and behavioural mediators. J Adv Nurs. 2010;66:1080-91.

44. Josefsson K, Aling J, Ostin B-L. What implies the good work for registered nurses in municipal elderly care in Sweden? Clin Nurs Res. 2011;20:292-309.

45. Report to the Minister of Health and Long-Term Care on Regulatory Issues and Matters respecting Personal Support Workers, September 2006. http:// www.hprac.org/en/reports/PSWreportSept06.asp. Accessed 15 Apr 2017.

46. Health Professions Regulatory Advisory Council (HPRAC). Regulation of health professions in Ontario: new directions. 2006. http://www.hprac.org/ en/reports/resources/New_Directions_April_2006_EN.pdf. Accessed 15 Apr 2017.

47. Pedhazur EJ, Pedhazur SL. Measurement, design, and analysis: an integrated approach. Hillsdale: Lawrence Erlbaum Associates; 1991.

48. Cohen J. A power primer. Psychol Bull. 1992;112:155-9.

49. Boucher P, Brookman C, Davies S, Denton M, VanderBent S, Zeytinoglu I. The PSW Health \& Safety Matters Survey, funded by the Ontario Ministry of Labour (grant \#13-R-030), 2015.

50. Canadian Community Health Survey (CCHS). 2013. http://www23.statcan.gc. ca/imdb/p2SV.pl?Function=getSurvey\&ld=144170. Accessed 15 Apr 2017.

51. Ontario Community Support Association press release, Facing funding freeze, Ontario's home and community care sector in jeopardy; 2017 Budget must include investments to build capacity and protect quality of home and community care. 2017. http://www.ocsa.on.ca/news/releasefacing-funding-freeze-ontarios-home-and-community-care-sector-injeopardy. Accessed Jan 2017.

52. Personal communications of Catherine Brookman with Executive Director Sujata Ganguli, St. Clair West Services for Seniors, and with Executive Director Odette Maharaj, TransCare Community Support Services. 2016.

53. 2017 Ontario budget, A stronger, healthier Ontario. Chapter III. Creating opportunities and security. http://www.fin.gov.on.ca/en/budget/ ontariobudgets/2017/budget2017.pdf (Last updated May 18, 2017, Accessed on 24 May 2017.)

54. Personal communication of Patricia Boucher (a co-investigator of the project and Research Advisory Committee member) with Matt Wilson (WSIB), June Harris (Program Associate, Workplace health and Safety Services, WSIB) and Carol Luce (Senior Business Analyst, Corporate Business Information \& Analytics, Strategy Cluster, WSIB), 2016.

\section{Submit your next manuscript to BioMed Central and we will help you at every step:}

- We accept pre-submission inquiries

- Our selector tool helps you to find the most relevant journal

- We provide round the clock customer support

- Convenient online submission

- Thorough peer review

- Inclusion in PubMed and all major indexing services

- Maximum visibility for your research

Submit your manuscript at www.biomedcentral.com/submit

C) Biomed Central 